\title{
A Generalized Log-Weibull Distribution with Bio-Medical Applications
}

\author{
C. Satheesh $\mathrm{Kumar}^{1, *}$ and Subha R. Nair ${ }^{2}$ \\ ${ }^{1}$ Department of Statistics, University of Kerala, Thiruvananthapuram, India \\ ${ }^{2}$ HHMSPB NSS College for Women, University of Kerala, Thiruvananthapuram, India
}

\begin{abstract}
Here we consider a generalized log-transformed version of the Weibull distribution and investigate some of its important properties like expressions for the cumulative distribution function hazard rate function, quantile function, characteristic function, raw moments, incomplete moments, etc. The distribution and moments of order statistics are obtained along with some results on certain structural properties of the distribution. The maximum likelihood estimation of the parameters of the distribution is attempted for both complete and censored data sets and the usefulness of the distribution is illustrated with the help of real-life data sets from biomedical fields.
\end{abstract}

Keywords: Hazard rate, Maximum likelihood estimation, Model selection, Order statistics, Reliability measures, Censored data.

\section{INTRODUCTION}

The generalized versions of Weibull distribution (WD) and their applications have gained much importance in fields of engineering, ecology, medicine, pharmacy, etc. due to the flexibility of these distributions in handling survival data. Many such modifications of the WD were considered by various researchers including [1-5], etc. An exponentiated version of the WD having the name 'the exponentiated Weibull distribution' was introduced by [6] to incorporate the bath-tub shape for its hazard rate function through the cumulative distribution function (c.d.f.)

$\mathrm{G}_{1}(\mathrm{y})=\left\{1-\mathrm{e}^{\left[-\sigma \mathrm{y}^{\beta}\right]}\right\}^{\delta}$,

for any $y>0$, with scale parameter $\sigma>0$ and shape parameters $\beta>0, \delta>0$. A distribution with c.d.f. (1) is hereby denoted as $\operatorname{EWD}(\sigma, \beta, \delta)$. Various properties of the distribution were further investigated in detail by several researchers like [7-9], etc. More recently, [10] considered certain properties of a log-transformed version of the one parametric Weibull distribution capable of dealing with truncated data sets using the name, 'the log-Weibull distribution (LWD)' with c.d.f.

$\mathrm{G}_{2}(\mathrm{y})=1-\mathrm{e}^{\left\{-[\ln (\mathrm{y})]^{\mathrm{c}}\right\}}$,

for $y>1$ and shape parameter $c>0$. The distribution with c.d.f. (2) is hereafter referred to as the LWD(c).

In this paper, we consider a generalized version of the $\operatorname{LWD}(\mathrm{c})$ using the name 'the generalized log-Weibull distribution (GLWD)'. It is seen that the GLWD possess five distinct shapes for its hazard rate

*Address correspondence to this author at the Department of Statistics, University of Kerala, Thiruvananthapuram, India; Tel: +919074108366;

E-mail: drcsatheeshkumar@gmail.com function including most of the monotone as well as non-monotone hazard rate shapes such as increasing, decreasing, bathtub, upside-down bathtub, and ' $S$ ' shapes and is more flexible in terms of its measures of central tendency, dispersion, skewness, and kurtosis, which highlights the utility of the model as a lifetime distribution. As such the proposed distribution can be considered to be a better alternative for many of the recently developed modifications of the WD. The paper is organized as follows: In section 2 we introduce the GLWD and discuss its important properties. In section 3 , some structural properties of the distribution are dealt with and Section 4 derives the distribution and moments of the order statistics of the GLWD. Section 5 contains the maximum likelihood estimation of the parameters of the distribution for complete and censored cases. In section 6 , the usefulness of the model is illustrated with the help of both complete and censored real-life data sets.

\section{GENERALIZED LOG-WEIBULL DISTRIBUTION: DEFINITION AND PROPERTIES}

Here we present the definition of the generalized log-Weibull distribution and discuss its important properties.

Definition 2.1 A continuous random variable $Y$ is said to have "the generalized log-Weibull distribution (GLWD)" if its c.d.f. is of the following form, for any $\alpha>0$, $\beta>0$ and $y>1$.

$F_{Y}(y)=\left\{1-e^{-[\ln (y)]^{\alpha}}\right\}^{\beta}$

Henceforth we write $\operatorname{GLWD}(\alpha, \beta)$ for denoting this distribution, it is necessary. When $\beta=1$, the $\operatorname{GLWD}(\alpha, \beta)$ reduces to the $\operatorname{LWD}(\alpha)$ with c.d.f $(2)$.

We give the expressions for the probability density function (p.d.f.) $f_{Y}(y)$, survival function $F_{Y}(y)$, the hazard rate function $h_{Y}(y)$ and the reversed hazard rate function $\tau_{Y}(y)$ of the $\operatorname{GLWD}(\alpha, \beta)$ as given below. 


$$
\begin{aligned}
& f_{Y}(y)=\frac{\beta \alpha}{y}[\ln (y)]^{\alpha-1} e^{-[\ln (y)]^{\alpha}}\left[1-e^{-[\ln (y)]^{\alpha}}\right]^{\beta-1}, \\
& \bar{F}_{Y}(y)=1-\left\{1-e^{-[\ln (y)]^{\alpha}}\right\}^{\beta}, \\
& h_{Y}(y)=\frac{\alpha \beta}{y}\left\{1-e^{-[\ln (y)]^{\alpha}}\right\}^{\beta-1} e^{-[\ln (y)]^{\alpha}}[\ln (y)]^{(\alpha-1)}\{1- \\
& {\left[1-e^{\left.-[\ln (y)]^{\alpha}\right]^{\beta}}\right\}^{-1}}
\end{aligned}
$$

and

$$
\tau_{Y}(y)=\frac{\alpha \beta}{y}\left\{1-e^{-[\ln (y)]^{\alpha}}\right\}^{-1} e^{-[\ln (y)]^{\alpha}}[\ln (y)]^{(\alpha-1)} .
$$

A practical interpretation of the $\operatorname{GLWD}(\alpha, \beta)$ can be provided whenever $\beta$ is an integer. Consider a device that is constituted of independent and identically distributed components having the $\operatorname{LWD}(\alpha)$ with c.d.f. (3), connected in a parallel system so that the device fails only if the last component in the system fails. Let $Y_{1}, Y_{2}, \ldots, \mathrm{Y}_{\beta}$ denote the lifetimes of the components and let $Y$ be the life of the system with c.d.f. $F_{Y}(y)$. Then

$$
\begin{aligned}
F_{Y}(y) & =\mathrm{P}(\mathrm{Y} \leq \mathrm{y})=\mathrm{P}\left(Y_{1} \leq \mathrm{y}, Y_{2} \leq \mathrm{y}, \ldots, Y_{\beta} \leq \mathrm{y}\right) \\
& =\left[\mathrm{P}\left(Y_{1} \leq \mathrm{y}\right)\right]^{\beta}=\left[\mathrm{G}_{2}(\mathrm{y})\right]^{\beta} .
\end{aligned}
$$

Clearly, in the light of (3), the lifetime of the device has the $\operatorname{GLWD}(\alpha, \beta)$.

The plots of the p.d.f., the c.d.f. and the hazard rate function of the $\operatorname{GLWD}(\alpha, \beta)$ for particular values of its parameters are presented in Figures 1, 2, and $\mathbf{3}$

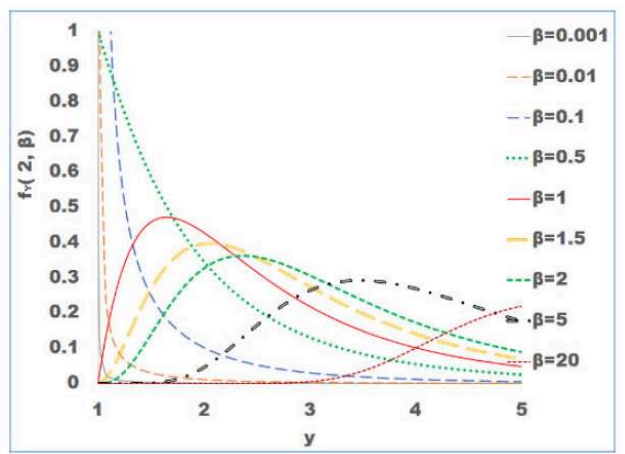

(a)

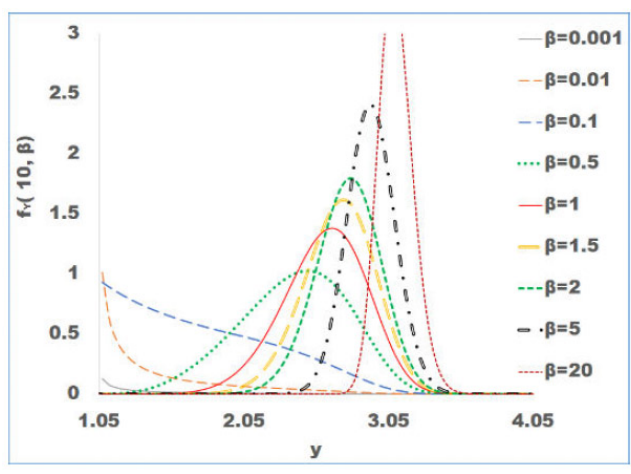

(c) respectively. Based on Figures 1, 2, and 3 we have the following observations regarding the shapes of the c.d.f., p.d.f. and hazard rate function of the $\operatorname{GLWD}(\alpha, \beta)$

- $\quad$ From Figure 1 it can be observed that the p.d.f. of the $\operatorname{GLWD}(\alpha, \beta)$ is a decreasing function for values of $\alpha$ and $\beta$ such that $\alpha \beta<1$ whereas the p.d.f. is unimodal when $\alpha \beta>1$.

- $\quad$ Figure 2 reveals that the c.d.f. $F_{Y}($.$) of the$ $\operatorname{GLWD}(\alpha, \beta)$ coincides at the point $\left(e, 0.63212^{\beta}\right)$ for fixed values of the parameter $\beta$ and various values of $\alpha$.

- $\quad$ From Figure 3, it is clear that the hazard rate function takes five different shapes including decreasing, increasing, bathtub shape, S-shape, and upside-down bathtub shape depending on the values of the parameters $\alpha$ and $\beta$, which illustrates the flexibility of the distribution to model data sets.

On inverting the c.d.f. $F_{\mathrm{Y}}\left(y_{p}\right)$ of the $\operatorname{GLWD}(\alpha, \beta)$, we obtain the expression for the quantile function $y_{p}$ in which $p$ is a Uniform $(0,1)$ random variable as

$\left.y_{p}=e^{\left\{\left[-\ln \left(1-p^{\beta^{-1}}\right)\right]^{\alpha^{-1}}\right.}\right\}$.

On substituting $p=0.5$ in (7), we obtain the median $(\mathrm{M})$ of the $\operatorname{GLWD}(\alpha, \beta)$ as

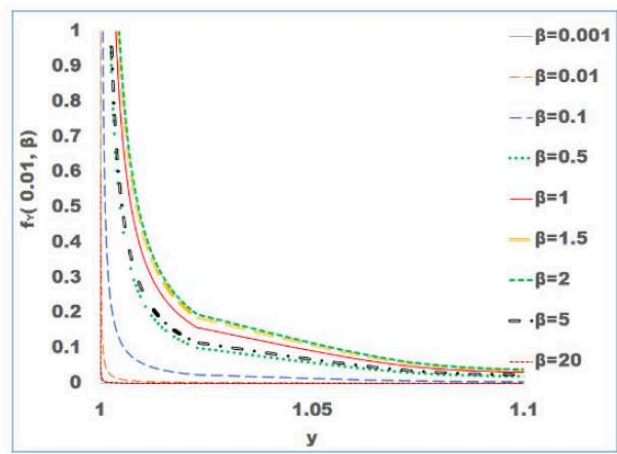

(b)

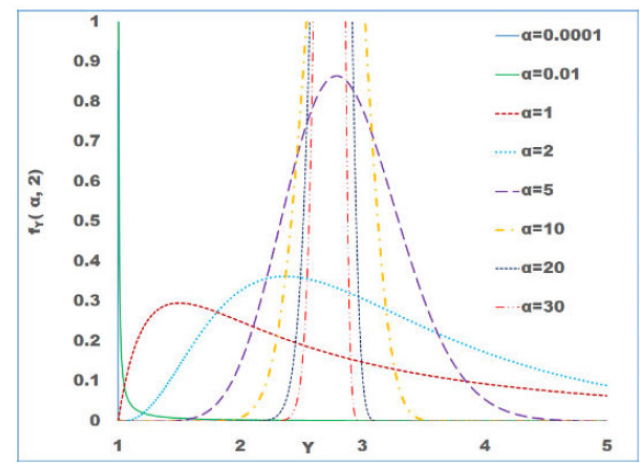

(d)

Figure 1: Plots of the p.d.f. of the GLWD for particular values of its parameters.

(a) Shapes of the p.d.f. for $\alpha=0.01$ and particular values of $\beta$. (b) Shapes of the p.d.f. for $\alpha=2$ and particular values of $\beta$. (c) Shapes of the p.d.f. for $\alpha=10$ and particular values of $\beta$. (d) Shapes of the p.d.f. for $\beta=2$ and particular values of $\alpha$. 


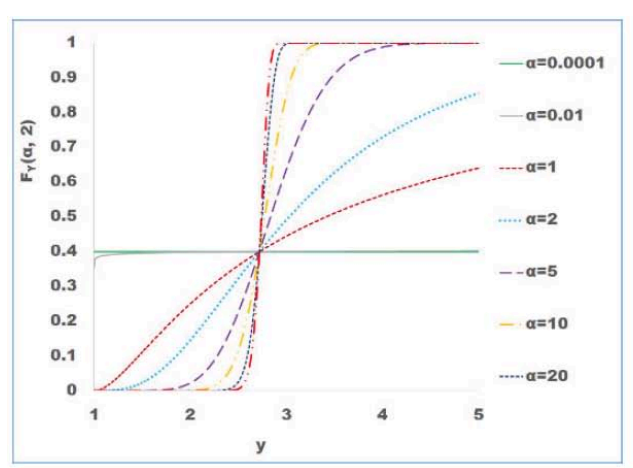

(a)

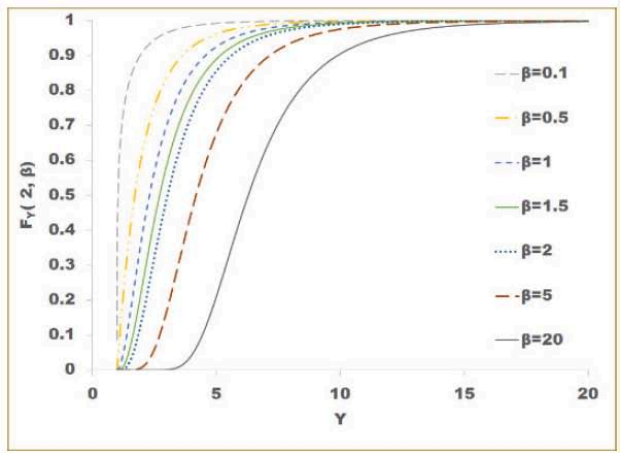

(b)

Figure 2: Plots of the c.d.f. of the GLWD for particular values of its parameters.

(a) Shapes of the c.d.f. for $\beta=2$ and particular values of $\alpha$. (b) Shapes of the c.d.f. for $\alpha=2$ and particular values of $\beta$.

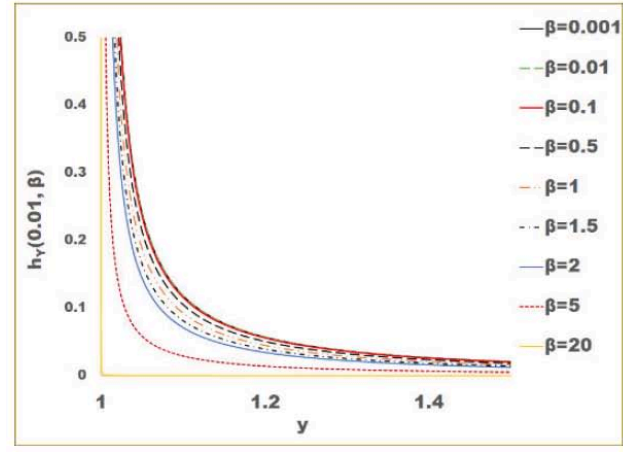

(a)

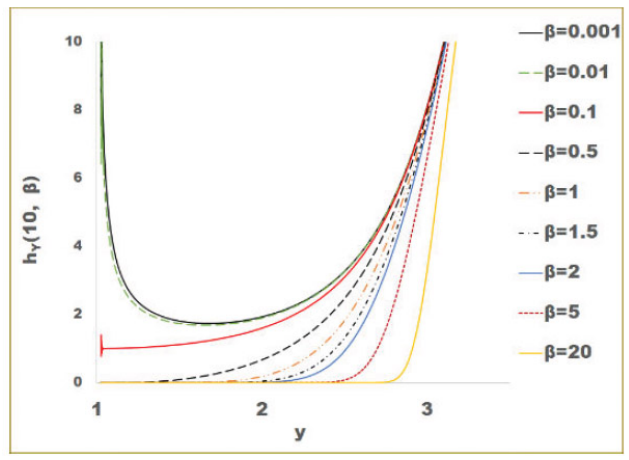

(c)

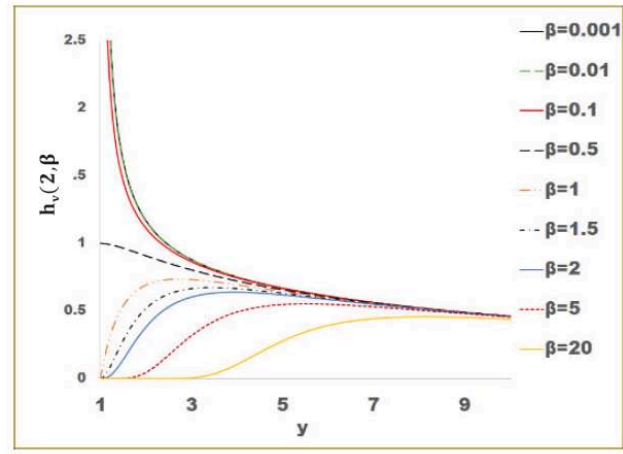

(b)

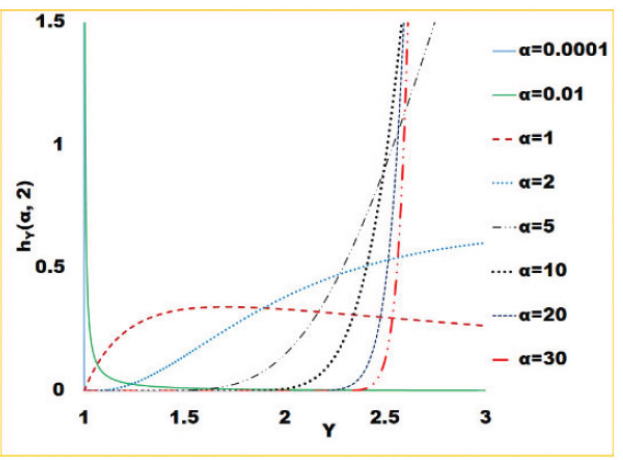

(d)

Figure 3: Plots of the hazard rate function of the GLWD for particular values of its parameters.

(a) Shapes of the hazard rate function for $\alpha=0.01$ particular values of $\beta$. (b) Shapes of the hazard rate function for $\alpha=2$ and particular values of $\beta$. (c) Shapes of the hazard rate function for $\alpha=10$ particular values of $\beta$. (d) Shapes of the hazard rate function for $\beta=2$ and particular values of $\alpha$.

$\left.M=e^{\left\{\left[-\ln \left(1-0.5^{\beta^{-1}}\right)\right]^{\alpha^{-1}}\right.}\right\}$

Also on differentiating the p.d.f. (4) for y, we have $\mathrm{f}_{\mathrm{Y}}^{\prime}(\mathrm{y})=$ $\mathrm{f}_{\mathrm{Y}}(\mathrm{y}) \mathrm{y}^{-1}\left\{[\ln (\mathrm{y})]^{-1}\left[\alpha\left(1-[\ln (\mathrm{y})]^{\alpha} \frac{1-\beta \mathrm{e}^{-[\ln (\mathrm{y})]^{\alpha}}}{1-\mathrm{e}^{-[\ln (\mathrm{y})]^{\alpha}}}\right)-1\right]-\right.$ $1\}$.

The mode of the $\operatorname{GLWD}(\alpha, \beta)$ is obtained from (8), as the solution of the equation $f^{\prime}{ }_{Y}(y)=0$, which reduces to

$$
\begin{aligned}
& (\alpha-1)[\ln (y)]^{-1}-\alpha[\ln (y)]^{\alpha-1}+ \\
& \alpha(\beta-1)[\ln (y)]^{\alpha-1}\left\{\mathrm{e}^{[\ln (\mathrm{y})]^{\alpha}}-1\right\}-1=0 .
\end{aligned}
$$

Using the condition for unimodality, it can be observed that the $\operatorname{GLWD}(\alpha, \beta)$ is unimodal if $\frac{d^{2} f_{Y}^{\prime}(y)}{d y^{2}}<$ 0 , which on simplification reduces to

$\left[1-\frac{\alpha-1}{[\ln (\mathrm{y})]}\right]\left[\frac{1-\beta \mathrm{e}^{-[\ln (\mathrm{y})]^{\alpha}}}{1-\mathrm{e}^{-[\ln (\mathrm{y})]^{\alpha}}}\right]+1 \leq$

$\frac{\alpha}{[\ln (\mathrm{y})]}\left[\alpha(\mathrm{d}-1) \frac{[\ln (\mathrm{y})]^{2 \alpha-1} \mathrm{e}^{-[\ln (\mathrm{y})]^{\alpha}}}{\left[1-\mathrm{e}^{-[\ln (\mathrm{y})]^{\alpha}}\right]^{2}}+\frac{\alpha-1}{\alpha}\left[\frac{1}{[\ln (\mathrm{y})]}-1\right]\right]$. 
The following observations can be made on the values of the modes of the $\operatorname{GLWD}(\alpha, \beta)$ for various values of $\alpha$ and $\beta$.

- When $\beta=1$ and $\alpha<1$ such that $\alpha \beta<1$.

In this case, the p.d.f. of the $\operatorname{GLWD}(\alpha, \beta)$ is a decreasing function of $y$.

- When $\beta=1$ and $\alpha>1$ such that $\alpha \beta>1$.

In this case the p.d.f. is unimodal in shape and the mode $\left(M_{0}\right)$ is obtained from (9)

as the solution of the equation $\left[\ln \left(\mathrm{M}_{\mathrm{o}}\right)\right]^{\alpha}=1-$ $\frac{\left[\ln \left(\mathrm{M}_{\mathrm{o}}\right)\right]+1}{\alpha}$.

- When $\alpha=1$ and $\beta>1$ such that $\alpha \beta>1$.

Here, the p.d.f. of the $\operatorname{GLWD}(\alpha, \beta)$ is unimodal in shape and the mode is obtained

from (9) as $M_{0}=\left[\frac{\beta+1}{\beta-1}\right]$.

- When $\alpha=1, \beta<1$ or $\alpha<1, \beta<1$ such that $\alpha \beta<1$.

In both these cases, the p.d.f. is a decreasing function of $y$.

- When $\alpha<1$ and $\beta>1$ such that $\alpha \beta>1$.

In this case, the p.d.f. of the $\operatorname{GLWD}(\alpha, \beta)$ is unimodal and $M_{o}$ is obtained from (9) as the solution of the equation $\left[\ln \left(M_{0}\right)\right]\left\{1+\frac{\alpha(\beta+1)}{2}\left[\ln \left(M_{0}\right)\right]^{\alpha}\right\}=$ $\alpha \beta-1$.

Moreover, differentiating the reversed hazard rate function (6) concerning y, we have

$\tau_{Y}^{\prime}(y)=\tau_{Y}(y) y^{-1}\left\{(\alpha-1)[\ln (y)]^{-1}-\alpha \frac{[\ln (y)]^{\alpha-1}}{1-e^{-[\ln (y)]^{\alpha}}}-1\right\}$.

Based on (10) we have the following result on the log-concavity of the c.d.f. of the $\operatorname{GLWD}(\alpha, \beta)$, the proof of which is straightforward and hence omitted.

Result 2.1 The c.d.f. $F_{Y}(y)$ of the $\operatorname{GLWD}(\alpha, \beta)$ is log-concave if $\frac{[\ln (y)]^{\alpha}}{1-e^{\left[-(\ln (y))^{\alpha}\right]}}>1-\frac{[\ln (y)]+1}{\alpha}$.

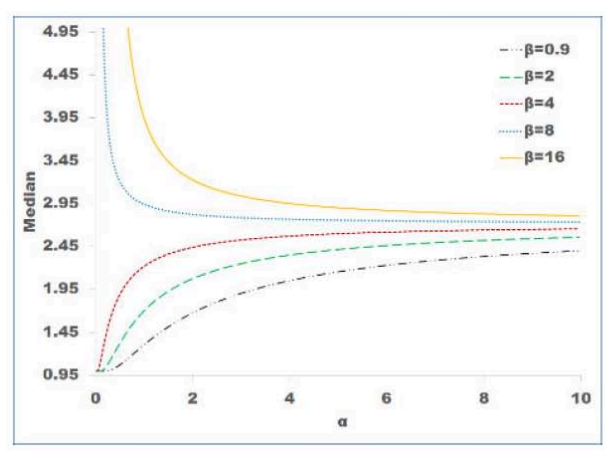

(a)
We have plotted the values of the median and mode of the $\operatorname{GLWD}(\alpha, \beta)$ for arbitrary values of $\beta$ and particular values of the parameter $\alpha$ (Figure 4).

Now we present certain series representations and integrals which we require in the sequel for deriving expressions for the characteristic function and moments of the $\operatorname{GLWD}(\alpha, \beta)$.

$\sum_{\mathrm{k}=0}^{\infty} \sum_{\mathrm{j}=0}^{\infty} \mathrm{B}(\mathrm{j}, \mathrm{k})=\sum_{\mathrm{k}=0}^{\infty} \sum_{\mathrm{j}=0}^{\mathrm{k}} \mathrm{B}(\mathrm{j}, \mathrm{k}-\mathrm{j})$

Also, for any a $\in \mathcal{R}$,

$(1+x)^{a}=\sum_{j=0}^{\infty}(a+1-j)_{j} \frac{x^{j}}{j !}$,

in which $(z)_{k}=\mathrm{z}(\mathrm{z}+1) \ldots(\mathrm{z}+\mathrm{k}-1)$, for $\mathrm{k} \geq 1$ with $(\mathrm{z})_{0}=1$.

The incomplete Gamma function $\gamma(\lambda, \mathrm{z})$ is defined as

$\int_{0}^{u} z^{v-1} e^{-\lambda z} d z=\lambda^{-v} \gamma(v, \lambda u)$.

The expressions of the characteristic function and the $r^{\text {th }}$ raw moment of the $\operatorname{GLWD}(\alpha, \beta)$ are obtained through the following results, the proofs of which are provided in Appendix A.

Result 2.2 The characteristic function of the $\operatorname{GLWD}(\alpha, \beta)$ is

$\Phi_{Y}(t)=$

$\beta \sum_{k=0}^{\infty} \sum_{j=0}^{\infty} \sum_{m=0}^{j} \frac{(\beta-m)_{m}(-1)^{m}(k b)^{j-m} e^{a k} \Gamma\left[\alpha^{-1}(j-m)+1\right]}{m !(j-m) !(m+1)^{\left[\alpha^{-1}(j-m)+1\right]}} \frac{(i t)^{k}}{k !}$,

when $\operatorname{Re}\left[\left\{\mathrm{a}^{-1}(\mathrm{j}-\mathrm{m})+1\right\}\right]>0, \mathrm{t} \in \mathcal{R}$ and $i=\sqrt{-1}$.

Remark 2.1 As a special case, when $\alpha=2$, using equations (3.462) and (9.254) in [11], the characteristic function of the $\operatorname{GLWD}(2, \beta)$ for $D_{-2}(a)=-\sqrt{\pi / 2} e^{\left(\frac{a^{2}}{4}\right)}\left[\sqrt{\pi / 2} e^{\left(-\frac{a^{2}}{2}\right)}-a\left(1-\phi^{\prime}(a / \sqrt{2})\right)\right]$ is $\Phi_{Y}(t)=\left\{\begin{array}{l}\sum_{k=0}^{\infty}\left[\frac{(i t)^{k}}{k !} \sum_{i=0}^{\beta-1}\left(\begin{array}{c}\beta-1 \\ i\end{array}\right) \frac{(-1)^{i}}{i+1} e^{\left[\frac{(i t)^{2}}{8(i+1)}\right]} D_{-2}\left[\frac{-(i t)}{\sqrt{2}(i+1)}\right]\right], \text { if } \beta \in N \\ \sum_{k=0}^{\infty}\left[\frac{(i t)^{k}}{k !} \sum_{i=0}^{\infty} \frac{(\beta-i)^{2}}{i !} \frac{(-1)^{i}}{i+1} e^{\left[\frac{(i t)^{2}}{8(i+1)}\right]} D_{-2}\left[\frac{-(i t)}{\sqrt{2}(i+1)}\right]\right], \text { if } \beta \notin N\end{array}\right.$

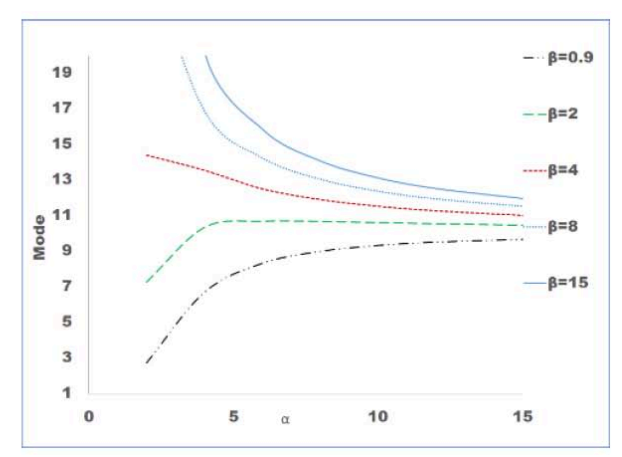

(b)

Figure 4: Plots of the median and mode of the GLWD for particular values of its parameters.

(a) Median of the GLWD for particular values of $\alpha$ and $\beta$. (b) Mode of the GLWD for particular values of $\alpha$ and $\beta$. 
in which $\varphi($.$) is the standardized normal distribution$ function.

Result 2.3 The $\mathrm{r}^{\text {th }}$ raw moment of the $\operatorname{GLWD}(\alpha, \beta)$ is given by

$\mu_{r}(y)=\left\{\begin{array}{c}\beta \sum_{k=0}^{\infty} A_{k}(\alpha, \beta) \Gamma\left(\frac{k}{\alpha}+1\right), \text { if } \beta \in N \\ \beta \sum_{k=0}^{\infty} B_{k}(\alpha, \beta) \Gamma\left(\frac{k}{\alpha}+1\right), \text { if } \beta \notin N,\end{array}\right.$

where $\quad A_{k}(\alpha, \beta)=1+\sum_{j=1}^{\beta-1} \frac{(-1)^{j}\left(\begin{array}{c}\beta-1 \\ j\end{array}\right)}{(j+1)^{\left(k \alpha^{-1}+1\right)}}, B_{k}(\alpha, \beta)=1+$ $\sum_{j=1}^{\infty} \frac{(-1)^{j}(\beta-k)_{k}}{j !(j+1)^{\left(k \alpha^{-1}+1\right)}}$ and $\mathrm{N}$ is the set of natural numbers.

The expressions for $\mu_{r}$ and $\Phi_{Y}(t)$ is seen to converge for all values of $r \in N$ as well as the parameters of the $\operatorname{GLWD}(\alpha, \beta)$. It has also been verified that the values of the raw moments of the GLWD can be calculated numerically using statistical packages like MATHEMATICA and MATHCAD. We derive the expression for the $r^{\text {th }}$ incomplete raw moment of the $\operatorname{GLWD}(\alpha, \beta)$ through the following result.

Result 2.4 The expression for the $\mathrm{r}^{\text {th }}$ incomplete raw moment of the $\operatorname{GLWD}(\alpha, \beta)$ can be obtained as $\Delta_{r}(t)=$ $\beta \sum_{k, j=0}^{\infty} \frac{(r)^{k}(-1)^{j}(\beta-j)_{j}(j+1)^{-\left(\frac{k}{\alpha}+1\right)}}{j ! k !} \gamma\left(\left[\frac{k}{\alpha}+1\right],(j+\right.$ 1) $\left.(\ln (t))^{\alpha}\right)$,

in which $\mathrm{y}(\lambda, \mathrm{z})$ is the incomplete Gamma function as defined in (13).

Proof. The $\mathrm{r}^{\text {th }}$ incomplete raw moment $\Delta_{r}(t)$ is given by

$\Delta_{r}(t)=\mathrm{E}\left(\mathrm{Y}^{\mathrm{r}} / \mathrm{Y}<t\right)=$

$\alpha \beta \int_{1}^{\mathrm{t}} \mathrm{y}^{\mathrm{r}} \mathrm{y}^{-1}\left\{1-\mathrm{e}^{\left[-[\ln (\mathrm{y})]^{\alpha}\right]}\right\}^{\beta-1} \mathrm{e}^{\left[-[\ln (\mathrm{y})]^{\alpha}\right]}[\ln (\mathrm{y})]^{(\alpha-1)} \mathrm{dy}$.

By using the substitution $z=[\ln (y)]^{\alpha}$ in (17), we obtain

$\Delta_{\mathrm{r}}(\mathrm{t})=\sum_{\mathrm{k}=0}^{\infty}\left[\frac{(\mathrm{r})^{\mathrm{k}}}{\mathrm{k} !} \beta \int_{0}^{(\ln (\mathrm{t}))^{\alpha}} \mathrm{z}^{\mathrm{k} \alpha^{-1}} \mathrm{e}^{-\mathrm{z}}\left(1-\mathrm{e}^{-\mathrm{z}}\right)^{\beta-1} \mathrm{dz}\right]$.

On simplifying (18) in the light of (12) and (13), we obtain (16).

We obtain the expressions for the mean deviations about the mean and the median of the $\operatorname{GLWD}(\alpha, \beta)$ with c.d.f. $F_{Y}($.$) , in terms of its r^{\text {th }}$ incomplete moment, $\Delta_{r}($. can be obtained as

$\mathrm{E}\left(\left|\mathrm{Y}-\mu_{1}\right|\right)=2 \mu_{1} \mathrm{FY}\left(\mu_{1}\right)-2 \Delta_{1}\left(\mu_{1}\right)$ and $\mathrm{E}(\mid \mathrm{Y}-$ $\mathrm{M} \mid)=\mathrm{M}-2 \Delta_{1}(\mathrm{M})$ respectively, where $\Delta_{1}(\mathrm{t})$ is as defined in (16), when $r=1$.

Now we present certain expressions for the percentile measures of skewness and kurtosis of the $\operatorname{GLWD}(\alpha, \beta)$. Percentile measures of skewness and kurtosis of distribution are less affected by the tail behaviour of the distribution or by outliers (see [12]) and find use in cases where the moment measures are infinite. Galton's and Bowley's measures of skewness, $\mathrm{S}_{\mathrm{G}}$, and $\mathrm{S}_{\mathrm{B}}$ are defined as

$S_{G}=\frac{y_{0.8}-y_{0.5}}{y_{0.5}-y_{0.2}}$

and

$S_{B}=\frac{\left(y_{0.75}-y_{0.5}\right)-\left(y_{0.5}-y_{0.25}\right)}{y_{0.75}-y_{0.25}}$,

while the expression for the Schmid - Trede measure of kurtosis $L$ is

$L=\frac{y_{0.975}-y_{0.025}}{y_{0.75}-y_{0.25}}$,

in which $y_{p}$ is the $p^{\text {th }}$ quantile of the $\operatorname{GLWD}(\alpha, \beta)$ as given in (7). The percentile measures of skewness and kurtosis of the $\operatorname{GLWD}(\alpha, \beta)$ are obtained through the following results, the proofs of which follow directly from (19), (20), and (21) respectively, in the light of (9). We have also calculated the values of $S_{G}, S_{B}$, and $L$ of the $\operatorname{GLWD}(\alpha, \beta)$ for particular values of its parameters and plotted them in Figure $\mathbf{5}$.

Result 2.5 The Galton's and Bowley's percentile measures of skewness, denoted by $S_{G}$ and $S_{B}$ respectively, of the GLWD are given by

$\frac{\left\{e^{\left(\eta_{0.75}-\eta_{0.5}\right)}+e^{\left(\eta_{0.25}-\eta_{0.5}\right)}-2\right\}}{e^{\left(\eta_{0.75}-\eta_{0.5}\right)}-e^{\left(\eta_{0.25}-\eta_{0.5}\right)}}$, in which $\eta_{p}=[-\ln (1-$ $\left.\left.p^{\beta^{-1}}\right)\right]^{\alpha^{-1}}$, for $0<\mathrm{p}<1$.

Result 2.6 For the $\operatorname{GLWD}(\alpha, \beta)$, the Schmid-Trede percentile measure of kurtosis $(L)$ is given by $\mathrm{L}=\frac{e^{\eta_{0.975}}-e^{\eta_{0.025}}}{e^{\eta_{0.75}}-e^{\eta_{0.25}}}$, where $\eta_{\mathrm{p}}$ is as defined in Result 2.5.

In the light of Results 2.5 and 2.6, we have the following observations.

- The GLWD is symmetric when $e^{\eta_{0.8}}+e^{\eta_{0.2}}=$ $2 e^{\eta_{0.5}}$ and is negatively (or positively) skewed if $e^{\eta_{0.8}}+e^{\eta_{0.2}}$ is less than (or greater than) $2 e^{\eta_{0.5}}$.

- The GLWD is mesokurtic when $e^{\eta_{0.975}}$ $e^{\eta_{0.025}}=2.9058\left(e^{\eta_{0.75}}-e^{\eta_{0.25}}\right) \quad$ andplatykurtic (or leptokurtic) when $e^{\eta_{0.975}}-e^{\eta_{0.025} \text { is less than }}$ ( or greater than) 2.9058 $\left(e^{\eta_{0.75}}-e^{\eta_{0.25}}\right)$.

The following result gives an expression for the geometric mean $(\mathrm{GM})$ of the $\operatorname{GLWD}(\alpha, \beta)$, the proof of which follows directly from the definition of the $G M$ as $\ln (\mathrm{GM})=\mathrm{E}[\ln (\mathrm{Y})]$.

Result 2.7 The GM of the $\operatorname{GLWD}(\alpha, \beta)$ is $\ln (G M)=$
$\left\{\begin{array}{c}\beta \Gamma\left[1+\frac{1}{\alpha}\right] \sum_{k=0}^{\beta-1}\left(\begin{array}{c}\beta-1 \\ k\end{array}\right)(-1)^{k}(k+1)^{\frac{-1}{\alpha}-1}, \text { if } \beta \in N \\ \beta \Gamma\left[1+\frac{1}{\alpha}\right] \sum_{k=0}^{\infty}(\beta-k)_{k}(-1)^{k}(k+1)^{\frac{-1}{\alpha}-1}, \text { if } \beta \notin N .\end{array}\right.$ 


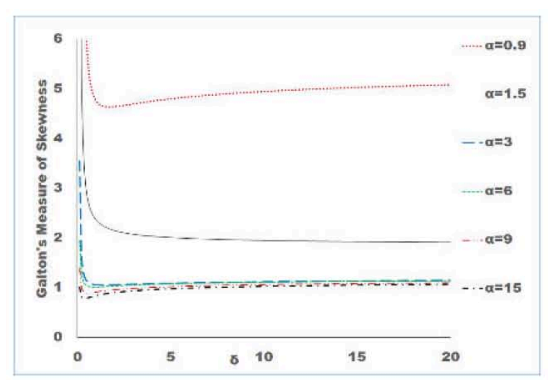

(a)

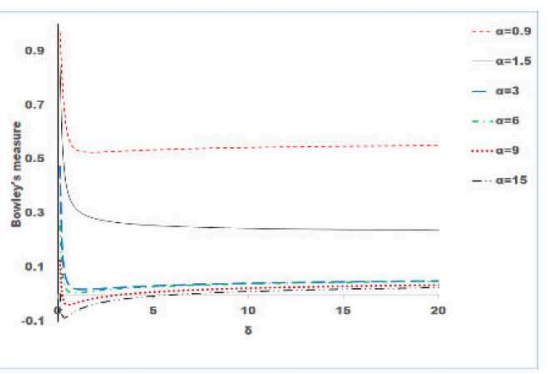

(b)

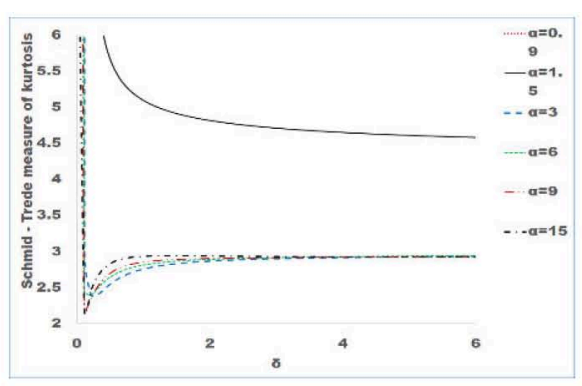

(c)

Figure 5: Plots of the percentile measures of skewness and kurtosis of the GLWD for arbitrary values of its parameters.

(a) Galton's measure of skewness. (b) Bowley's measure of Skewness. (c) Schmid-Trede measure of Kurtosis.

The stress-strength reliability concept, initially considered by [13] is used for describing the life of a component having strength $Y_{2}$, subjected to a stress $Y_{1}$, where both $Y_{1}$ and $Y_{2}$ are random variables. The component fails if $Y 1>Y 2$ and will survive otherwise. The stress-strength reliability measure $R$, defined as

$R=P\left(Y_{1}<Y_{2}\right)$

is the probability that a randomly selected device functions successfully and is a measure of component reliability, having significant applications in areas of engineering, genetics, psychology, physics, and economics. We obtain expressions for the stress-strength reliability measure $R$ of the $\operatorname{GLWD}(\alpha, \beta)$ for fixed values of its parameters through the following results.

Result 2.8 Let $Y_{i}$ be a random variable following the $\operatorname{GLWD}\left(\alpha_{i}, \beta_{i}\right)$, for $i=1,2$; with p.d.f. $f_{Y}($.$) as defined in (4).$ Then the stress-strength reliability measure $R$ is the following, in which $\beta(p, q)$ is the Beta function.

$$
\mathrm{R}=\beta_{2} \sum_{k=0}^{\infty}\left(\beta_{1}-k+1\right)_{k} \frac{(-1)^{k}}{k !} \beta\left(\alpha_{1} \alpha_{2}^{-1} k+1, \beta_{2}\right)
$$

Proof. By the definition of R as given in (22),

$$
\begin{aligned}
& \mathrm{R}=\int_{1}^{\infty}\left(\int_{1}^{\mathrm{y}_{2}} \mathrm{f}_{1}\left(\mathrm{y}_{1}\right) d \mathrm{y}_{1}\right) \mathrm{f}_{2}\left(\mathrm{y}_{2}\right) d \mathrm{y}_{2} \\
& = \\
& \beta_{2} \alpha_{2} \int_{1}^{\infty} \mathrm{y}_{2}^{-1}\left\{1-\mathrm{e}^{\left[-\left[\ln \left(\mathrm{y}_{2}\right)\right]^{\alpha_{1}}\right]}\right\}^{\beta_{1}}\{1- \\
& \left.\mathrm{e}^{\left[-\left[\ln \left(\mathrm{y}_{2}\right)\right]^{\alpha_{2}}\right]}\right\}^{\beta_{2}-1} \mathrm{e}^{\left[-\left[\ln \left(\mathrm{y}_{2}\right)\right]^{\alpha_{2}}\right]}\left[\ln \left(\mathrm{y}_{2}\right)\right]^{\left(\alpha_{2}-1\right)} \mathrm{dy}_{2} .
\end{aligned}
$$

Integrating (24) using the substitution $z=e^{-\ln \left(y_{2}\right)^{\alpha_{2}}}$, we get (23) in the light of (12).

Result 2.9 When $Y_{i}$ follows the $\operatorname{GLWD}\left(\alpha, \beta_{i}\right)$, for $\mathrm{i}=1,2$; with p.d.f. $\mathrm{f}_{\mathrm{Y}}($.$) as defined in (4), the system$ reliability $R=\frac{\beta_{2}}{\beta_{1}+\beta_{2}}$.

Proof. By definition,

$$
\mathrm{R}=\int_{1}^{\infty}\left(\int_{1}^{\mathrm{y}_{2}} \mathrm{f}_{1}\left(\mathrm{y}_{1}\right) d \mathrm{y}_{1}\right) \mathrm{f}_{2}\left(\mathrm{y}_{2}\right) d \mathrm{y}_{2}
$$

$$
\begin{aligned}
& =\beta_{2} \alpha_{2} \int_{1}^{\infty} \mathrm{y}_{2}^{-1}\{1 \\
& \left.-\mathrm{e}^{\left[-\left[\ln \left(\mathrm{y}_{2}\right)\right]^{\alpha_{1}}\right]}\right\}^{\beta_{1}+\beta_{2}-1} \mathrm{e}^{\left[-\left[\ln \left(\mathrm{y}_{2}\right)\right]^{\alpha_{2}}\right]}\left[\ln \left(\mathrm{y}_{2}\right)\right]^{\left(\alpha_{2}-1\right)} \mathrm{dy} y_{2} \\
& =\frac{\beta_{2}}{\beta_{1}+\beta_{2}} .
\end{aligned}
$$

From Result 2.8 and Result 2.9, it can be observed that the system reliability between two variables following the GLWD depends only on the values of those parameters that vary between the two variables.

We derive an expression for the mean residual life $(\mathrm{MRL})$ function of the $\operatorname{GLWD}(\alpha, \beta)$ through the following result.

Result from 2.10 The MRL function $M($.$) of the$ $\operatorname{GLWD}(\alpha, \beta)$ with c.d.f. $F_{Y}($.$) as defined in (3) and mean$ $\mu_{1}$ is the following,

$M(y)=\frac{1}{\bar{F}_{Y}(y)}\left\{\mu_{1}-y F_{Y}(y)+J_{1}(y)\right\}-y$,

in which for any for $y>1$,

$$
=\left\{\begin{array}{c}
\sum_{j=0}^{\infty} \sum_{k=0}^{\delta} \frac{\beta}{k}(-1)^{k} \frac{m}{\alpha j !} \gamma\left(\frac{j+1}{c},(\ln (y))^{\alpha}\right), \text { if } \beta \in N \\
\sum_{j, k=0}^{\infty}(\beta+1-k)_{k}(-1)^{k} \frac{m}{\alpha k ! j !} \gamma\left(\frac{j+1}{\alpha},(\ln (y))^{\alpha}\right), \text { if } \beta \notin N
\end{array}\right.
$$

where $\gamma(a, b)$ is the incomplete gamma function as given in (13).

Proof. By definition,

$$
M(y)=\frac{1}{\frac{F_{Y}(y)}{y}} \int_{y}^{\infty}(t-y) f_{Y}(t) d t=\frac{1}{\overline{\bar{F}_{Y}(y)}}\left[\int_{y}^{\infty} t f_{Y}(t) d t\right]-y
$$

By considering $I_{1}=\int_{1}^{\infty} t f_{Y}(t)=\mu_{1}$, the mean of the GLWD and $\mathrm{I}_{2}=\int_{1}^{\mathrm{y}} \mathrm{tf}_{\mathrm{Y}}(\mathrm{t}) \mathrm{dt}$, we can represent the integral $I=\int_{y}^{\infty} \mathrm{tf}_{\mathrm{Y}}(\mathrm{t}) \mathrm{dt}$ as $\mathrm{I}_{1}-\mathrm{I}_{2}$.

Then, $\mathrm{I}=\mu_{1}-\mathrm{I}_{2}$.

Now $\mathrm{I}_{2}$ can be written as $\mathrm{I}_{2}=y \mathrm{~F}_{\mathrm{Y}}(\mathrm{y})-\int_{1}^{\mathrm{y}} \mathrm{F}_{\mathrm{Y}}(\mathrm{t}) \mathrm{dt}=$ $y F_{Y}(y)-v_{1}(y)$, in which $v_{1}(y)$ can be evaluated using 
the binomial expansion or (12) depending on whether $\beta$ is an integer or a real number, respectively. Evaluating (26) using expressions for $\mathrm{I}_{1}$ and $\mathrm{I}_{2}$ gives (25).

\section{SOME STRUCTURAL PROPERTIES}

In this section, we present some structural properties of the $\operatorname{GLWD}(\alpha, \beta)$ through the following results. The proofs of Results 3.4 to 3.6 are omitted as they are straightforward and can be obtained directly by the method of transformation of variables.

Result 3.1 If $Y$ be any continuous random variable with c.d.f. $F_{Y}(y), F_{Y}(y)>0$, for every $y \in(1, \infty)$, then

$E\left\{-\ln \left[1-\left(1-e^{\left[-[\ln (y)]^{\alpha}\right]}\right)^{\beta}\right] / Y>x\right\}=-\ln [1-$ $\left.\left(1-e^{\left[-[\ln (x)]^{\alpha}\right]}\right)^{\beta}\right]+1$, for $\mathrm{y} \in[1, \infty)$ if and only if $\mathrm{Y}$ has the $\operatorname{GLWD}(\alpha, \beta)$.

Proof. The proof follows from Theorem 6 ([12], pp. 259) with

$\mathrm{h}(\mathrm{y})=-\ln \left[1-\left(1-\mathrm{e}^{\left[-[\ln (y)]^{\alpha}\right]}\right)^{\beta}\right] \quad$ and $\quad \mathrm{d}=$ $\exp \left[\left\{-\ln \left(1-\left(1-\mathrm{e}^{-1}\right)^{\beta^{-1}}\right)\right\}^{\alpha^{-1}}\right]$, since $\mathrm{h}(\mathrm{y})$ is strictly an increasing differentiable function in $[1, \infty]$ onto $[0, \infty)$ and $d$ is a positive constant with $h(d)=1$ so that for $y \in$ $[1, \infty)$,

$\mathrm{F}_{\mathrm{Y}}(\mathrm{y})=1-\mathrm{e}^{\left[\frac{-\mathrm{h}(\mathrm{y})}{\mathrm{h}(\mathrm{d})}\right]}=\left\{1-\mathrm{e}^{\left[-[\ln (y)]^{\alpha}\right]}\right\}^{\beta}$, which is the c.d.f. of the $\operatorname{GLWD}(\alpha, \beta)$.

Result 3.2 If $Y$ be any continuous random variable with c.d.f. $F_{Y}(y)$ for every $y \in(1, \infty)$, then

$E\left\{\ln \left[1-e^{\left[-[\ln (y)]^{\alpha}\right]}\right] / Y \leq x\right\}=\ln \left[1-e^{\left[-[\ln (x)]^{\alpha}\right]}\right]-\frac{1}{\beta}$, for $y \in[1, \infty)$ if and only if $Y$ has the $\operatorname{GLWD}(\alpha, \beta)$.

Proof. The proof follows from Theorem 9 ([12], pp. 264) with $\mathrm{h}(\mathrm{y})=\ln \left\{1-\mathrm{e}^{\left[-[\ln (y)]^{\alpha}\right]}\right\}$ and $\mathrm{d}=-\frac{1}{\beta}$ since $E(h(Y))=-\frac{1}{\beta}$, and $\lim _{\mathrm{y} \rightarrow \infty} \mathrm{h}(\mathrm{y})=0$ so that for $\mathrm{y} \in[1$, $\infty)$,

$\mathrm{F}_{\mathrm{Y}}(\mathrm{y})=\mathrm{e}^{\left[\frac{1}{\mathrm{~d}}[\mathrm{~h}(\infty)-\mathrm{h}(\mathrm{y})]\right]}=\left\{1-\mathrm{e}^{\left[-[\ln (y)]^{\alpha}\right]}\right\}^{\beta}$, which is the c.d.f. of $\operatorname{GLWD}(\alpha, \beta)$.

Result 3.3 The c.d.f. $F_{Y}(y)$ of the $\operatorname{GLWD}(\alpha, \beta)$ tends to the c.d.f. of the $\operatorname{EWD}(1, \alpha, \beta)$ for extremely small values of $y$.

Proof. The c.d.f. $F_{Y}(y)$ of the $\operatorname{GLWD}(\alpha, \beta)$ given in (3) can be written as the following, for $y>1$.

$\mathrm{F}_{\mathrm{Y}}(\mathrm{y})=\left\{1-\mathrm{e}^{[-\ln (\mathrm{y})]^{\alpha}}\right\}^{\beta}$

Using $y=1+t$ for extremely small $t>0$ in (27), we get

$\mathrm{F}_{\mathrm{Y}}(\mathrm{t})=\left\{1-\mathrm{e}^{[-\ln (1+\mathrm{t})]^{\alpha}}\right\}^{\beta}$
On expanding the term $\ln (1+t)$ in (28) and discarding the second term onwards, we obtain

$F_{Y}(t)=\left\{1-e^{(-t)^{\alpha}}\right\}^{\beta}$, which is the c.d.f. of the $\operatorname{EWD}(1, \alpha$, $\beta)$, as given in (1).

Result 3.4 For any $\alpha>0$ and $\beta>0$, the random variable $Y$ follows the $\operatorname{GLWD}(\alpha, \beta)$ if and only if $Z_{1}^{*}=\ln (y)$ follows the $\operatorname{EWD}(1, \alpha, \beta)$ having c.d.f. (1).

Result 3.5 For any $\alpha>0$ and $\beta>0$, the random variable $\mathrm{Y}$ follows the $\operatorname{GLWD}(\alpha, \beta)$ if and only if $Z_{2}^{*}=[\ln (y)]^{c}$ follows the exponentiated exponential distribution, $\operatorname{EED}(1, \beta)$ of $[14]$.

Result 3.6 For any $a \in(-\infty, \infty), b>0, \alpha>0$ and $\beta>0$, the random variable $Y$ follows the $\operatorname{GLWD}(\alpha, \beta)$ with p.d.f. (4), if and only if $Z_{3}^{*}=v Y ; v>0, \beta>0$ follows a four parametric version of the $\operatorname{GLWD}(\alpha, \beta)$ having c.d.f. $F_{Y}(y)=\left\{1-e^{-\left(b^{-1}[\ln (y)-a]\right)^{\alpha}}\right\}^{\beta}$, with $a=\ln (v)$, and $b=\beta$.

\section{DISTRIBUTION AND MOMENTS OF ORDER STATISTICS}

Let $Y_{i: n}$ be the $i^{\text {th }}$ order statistic based on a random sample $Y_{1}, Y_{2}, \ldots, Y_{n}$ of size $n$ of theGLWD $(\alpha, \beta)$, with p.d.f. $f_{Y}(y)=f_{Y}(y ; \beta)$ as given in (4) and let $\mu_{r}=\mu_{r}(\beta)$ be the $r^{\text {th }}$ raw moment of the $\operatorname{GLWD}(\alpha, \beta)$ as given in (15). The distribution and moments of $Y_{i: n}$ can now be derived through the following results.

Result 4.1 For $y>1$, the p.d.f. of the $i^{\text {th }}$ order statistic $Y_{i: n}$ is given by

$f_{i: n}(y)=\sum_{k=0}^{n-i} v_{n: i: k} f_{Y}\left(y ; \beta_{i k}^{*}\right)$

in which $\quad \beta_{i k}^{*}=\beta(k+i)-1$

and

$v_{n: i: k}=\frac{\left(\begin{array}{c}n \\ i-1\end{array}\right)\left(\begin{array}{c}n-i+1 \\ k\end{array}\right)(-1)^{k}(n-k-i+1) \beta}{(k+i)-1}$.

Proof. Consider a random sample of size $\mathrm{n}$ from an $\operatorname{GLWD}(\alpha, \beta)$ with p.d.f. $f_{Y}(y)$ and c.d.f. $F_{Y}(y)$. Then the p.d.f. of the $i^{\text {th }}$ order statistic $Y_{i: n}$ can be defined as

$f_{i: n}(y)=\frac{n !}{(i-1) !(n-i) !}\left[F_{Y}(y)\right]^{i-1}\left[1-F_{Y}(y)\right]^{n-i} f_{Y}(y)$.

By applying the binomial theorem in (30), we have

$f_{i: n}(y)=\frac{n !\left(\begin{array}{c}n-i \\ k\end{array}\right)}{(i-1) !(n-i) !}\left[F_{Y}(y)\right]^{i-1} f_{Y}(y) \sum_{k=0}^{n-i}(-1)^{k}\left[F_{Y}(y)\right]^{k}$

$=$
$\sum_{\mathrm{k}=0}^{\mathrm{n}-\mathrm{i}} \frac{\mathrm{n!}\left(\begin{array}{c}\mathrm{n}-\mathrm{i} \\ \mathrm{k}\end{array}\right)(-1)^{\mathrm{k}} \alpha \beta}{(\mathrm{i}-1) !(\mathrm{n}-\mathrm{i}) ! \mathrm{y}}\{1-$

$\left.\mathrm{e}^{\left[-[\ln (\mathrm{y})]^{\alpha}\right]}\right\}^{\beta(\mathrm{k}+\mathrm{i})-1} \mathrm{e}^{\left[-[\ln (\mathrm{y})]^{\alpha}\right]}[\ln (\mathrm{y})]^{(\alpha-1)}$.

On further simplification, (31) gives

$f_{i: n}(y)=\sum_{k=0}^{n-i} \frac{n !\left(\begin{array}{c}n-i \\ k\end{array}\right)}{(i-1) !(n-i) !}(-1)^{k} \frac{\beta}{\beta(k+i)-1} f_{Y}\left(y ; \beta_{i k}^{*}\right)$, 
which reduces to (29).

As a consequence of Result 4.1, we have the following corollaries.

Corollary 4.1 For $y>1$, the p.d.f. of the smallest order statistic $Y_{1: n}=\min \left(Y_{1}, Y_{2}, \ldots, Y_{n}\right)$ is

$f_{1: n}(y)=\sum_{k=0}^{n-1}\left(\begin{array}{c}n \\ k+1\end{array}\right) f_{Y}(y ;(k+1) \beta)$.

Corollary 4.2 For $y>1$, the largest order statistic $Y_{n: n}=\max \left(Y_{1}, Y_{2}, \ldots, Y_{n}\right)$ has the $\operatorname{GLWD}(\alpha, n \beta)$ with c.d.f. $F_{n: n}(y)=\left\{1-e^{-[\ln (y)]^{\alpha}}\right\}^{n \beta}$.

Corollary 4.3 The largest order statistic $Y_{n: n}$ follows the $\operatorname{GLWD}(c, n \beta)$ if and only if $Y_{1}$ follows the GLWD.

Corollary 4.4 For $y>1$, the p.d.f. of the median $Y_{m+1: n}$, for a sample of size $n=2 m+1$, is

$f_{(m+1: n)}(y)$

$=\sum_{k=0}^{m}(-1)^{k}\left(\begin{array}{c}2 m+1 \\ m\end{array}\right)\left(\begin{array}{l}m \\ k\end{array}\right) \frac{(m+1)}{m+k+1} f_{Y}(y ; \beta(m+k$ $+1))$.

Further, the $r^{\text {th }}$ raw moment of the $i^{\text {th }}$ order statistic $Y_{i: n}$ of the $\operatorname{GLWD}(\alpha, \beta)$ is provided through the following result, the proof of which follows from Results 2.3 and 4.1.

Result 4.2 The $r^{\text {th }}$ raw moment of $Y_{i: n}$ is

$\mu_{r(i: n)}(y)=\sum_{k=0}^{i-1} v_{n: i: k} \mu_{r}\left(\beta_{i k}^{*}\right)$,

in which $r>0$ and $v_{n: i: k}$ and $\beta_{i k^{*}}$ are as defined in (29).

\section{ESTIMATION}

In this section, we discuss the maximum likelihood estimation of the parameters of the $\operatorname{GLWD}(\alpha, \beta)$ and derive the likelihood equations for complete and right-censored cases. A data set of observations without any missing value is termed as an uncensored/complete set. The likelihood function for a complete data set having $X_{1}, X_{2}, \ldots, X_{n}$ is given by

$$
L_{1}(\Theta)=\prod_{i} f\left(x_{i}, \Theta\right)
$$

Censored data is regularly encountered in survival and reliability analysis as the information regarding the survival time of some of the observations understudy may remain incomplete or unknown. According to [15], censored data sets represent a particular type of missing data. Assume that we have a random sample of $n$ units with true survival times $\mathrm{T}_{1}, \mathrm{~T}_{2}, \ldots, \mathrm{T}_{\mathrm{n}}$ having p.d.f. $f(x)$ and c.d.f. $F(x)$. However, due to right censoring such as staggered entry, loss to follow-up, competing risks (death from other causes) or any combination of these, it might be impossible to observe the survival times in all of these $n$ cases. Thus, a subject can either be observed for its full lifetime or can be censored. Clearly, the observed data are the minimum of the survival time and censoring time for each unit. Assume that $\mathrm{C}_{1}, \mathrm{C}_{2}, \ldots, \mathrm{C}_{\mathrm{n}}$ are the censoring times of the $n$ units drawn independently of $T_{i}, i=1$, $2, \ldots, n$. On each of $n$ units, we observe $n$ random pairs $\left(X_{i}, \eta_{i}\right)$, in which $X_{i}=\min \left(T_{i}, C_{i}\right)$ and

$\eta_{i}=\left\{\begin{array}{l}1, \text { for } T_{i}<C_{i} \\ 0, \text { for } T_{i}>C_{i}\end{array}\right.$

for $\mathrm{i}=1,2, \ldots, \mathrm{n}$. Clearly $\eta_{i}$, the censorship indicator indicates whether $T_{i}$ is censored or not. Then, the likelihood function for the censored data set is given by

$\mathrm{L}_{2}(\Theta)=\prod_{\eta_{\mathrm{i}}=1} \mathrm{f}\left(\mathrm{x}_{\mathrm{i}} ; \Theta\right) \prod_{\eta_{\mathrm{i}}=0} \overline{\mathrm{F}}\left(\mathrm{x}_{\mathrm{i}} ; \Theta\right)$.

\subsection{Estimation of Parameters for the GLWD for Complete Data Sets}

Consider a random sample constituting of $Y_{1}, Y_{2}, \ldots$, $Y_{n}$ observations taken from the $\operatorname{GLWD}(\alpha, \beta)$. The log-likelihood function for the vector of parameters $\Theta=$ $(\alpha, \beta)$ is given by

$\mathrm{l}_{1}(\Theta)=$

$\sum_{\mathrm{i}=1}^{\mathrm{n}}\left\{\ln (\beta \alpha)-\ln \left(\mathrm{y}_{\mathrm{i}}\right)+(\beta-1) \ln \left\{1-\exp \left[-\left[\ln \left(\mathrm{y}_{\mathrm{i}}\right)\right]^{\alpha}\right]\right\}-\right.$

$\left.\left[\ln \left(\mathrm{y}_{\mathrm{i}}\right)\right]^{\alpha}+(\alpha-1) \ln \left(\ln \left(\mathrm{y}_{\mathrm{i}}\right)\right)\right\}$.

Differentiating the log-likelihood function (34) with respect to the parameters $\alpha$ and $\beta$ respectively, and equating to zero, we obtain the following likelihood equations.

$$
\frac{\mathrm{dl}_{1}(\Theta)}{\mathrm{d} \alpha}=\mathrm{n} \alpha^{-1}+\sum_{\mathrm{i}=1}^{\mathrm{n}} \ln \left[\ln \left(\mathrm{y}_{\mathrm{i}}\right)\right]\left\{1-\left[\ln \left(\mathrm{y}_{\mathrm{i}}\right)\right]^{\alpha} \mathrm{B}_{\Theta}\left(\mathrm{y}_{\mathrm{i}}\right)\right\}=0
$$

and

$$
\frac{\mathrm{dl}_{1}(\Theta)}{\mathrm{d} \beta}=\mathrm{n} \beta^{-1}+\sum_{\mathrm{i}=1}^{\mathrm{n}} \ln \left[1-\exp \left\{-\left[\ln \left(\mathrm{y}_{\mathrm{i}}\right)\right]^{\alpha}\right\}\right]=0,
$$

in which $\mathrm{B}_{\Theta}\left(\mathrm{y}_{\mathrm{i}}\right)=\frac{1-\beta \exp \left[-\left[\ln \left(\mathrm{y}_{\mathrm{i}}\right)\right]^{\alpha}\right]}{1-\exp \left[-\left[\ln \left(\mathrm{y}_{\mathrm{i}}\right)\right]^{\alpha}\right]}$.

\subsection{Estimation of Parameters for the $\operatorname{GLWD}(\alpha, \beta)$ for Censored Data Sets}

Let $r$ be the number of failures among the $n$ units. Then, using (4) and (3) in (33) the likelihood function of the $\operatorname{GLWD}(\alpha, \beta)$ for censored data set is given by

$$
\begin{aligned}
& \mathrm{L}_{2}(\Theta)=\prod_{\eta_{\mathrm{i}}=1} \beta \alpha \mathrm{y}_{\mathrm{i}}^{-1}\left[\ln \left(\mathrm{y}_{\mathrm{i}}\right)\right]^{\alpha-1} \exp \left\{-\left[\ln \left(\mathrm{y}_{\mathrm{i}}\right)\right]^{\alpha}\right\}\{1- \\
& \left.\exp \left\{-\left[\ln \left(\mathrm{y}_{\mathrm{i}}\right)\right]^{\alpha}\right\}\right\}^{\beta-1} \prod_{\eta_{\mathrm{i}}=0}\left[1-\left\{1-\exp \left[-\left(\ln \left(\mathrm{y}_{\mathrm{i}}\right)\right)^{\alpha}\right]\right\}^{\beta}\right]
\end{aligned}
$$

From (36), we obtain the corresponding log-likelihood function as

$$
\begin{aligned}
& \mathrm{l}_{2}(\Theta)= \\
& \mathrm{r} \ln (\alpha)+\mathrm{r} \ln (\beta)-\sum_{\eta_{\mathrm{i}}=1} \ln \left(\mathrm{y}_{\mathrm{i}}\right)-\sum_{\eta_{\mathrm{i}}=1}\left[\ln \left(\mathrm{y}_{\mathrm{i}}\right)\right]^{\alpha}+ \\
& (\alpha-1) \sum_{\eta_{\mathrm{i}}=1} \ln \left(\ln \left(\mathrm{y}_{\mathrm{i}}\right)\right)+(\beta-1) \sum_{\eta_{\mathrm{i}}=1} \ln \{1- \\
& \left.\exp \left[-\left[\ln \left(\mathrm{y}_{\mathrm{i}}\right)\right]^{\alpha}\right]\right\}+\sum_{\eta_{\mathrm{i}}=0} \ln \left\{1-\left\{1-\exp \left[-\left[\ln \left(\mathrm{y}_{\mathrm{i}}\right)\right]^{\alpha}\right]\right\}^{\beta}\right\} .
\end{aligned}
$$


Differentiating (37) with respect to the parameters $\alpha$ and $\beta$, we have the following likelihood equations for censored observations.

$\underline{\mathrm{dl}_{2}(\Theta)}$

$=\frac{\mathrm{d} \alpha}{\alpha}+\sum_{\eta_{\mathrm{i}}=1} \ln \left[\ln \left(\mathrm{y}_{\mathrm{i}}\right)\right]\left[1-\left[\ln \left(\mathrm{y}_{\mathrm{i}}\right)\right]^{\alpha} \mathrm{B}_{\Theta}\left(\mathrm{y}_{\mathrm{i}}\right)\right]$

$-\beta \sum_{\eta_{i}=0} \frac{\left\{1-\exp \left[-\left[\ln \left(\mathrm{y}_{\mathrm{i}}\right)\right]^{\alpha}\right]\right\}^{\beta-1} \exp \left[-(\ln (\mathrm{x}))^{-\alpha}\right]\left[\ln \left(\mathrm{y}_{\mathrm{i}}\right)\right]^{-\alpha} \ln [\ln (\mathrm{x})]}{1-\left\{1-\exp \left[-\left[\ln \left(\mathrm{y}_{\mathrm{i}}\right)\right]^{\alpha}\right]\right\}^{\beta}}$ and

$\underline{\mathrm{dl}_{2}(\Theta)}$

$=\frac{\mathrm{d} \beta}{\beta}+\sum_{\eta_{\mathrm{i}}=1} \ln \left\{1-\exp \left[-\left[\ln \left(\mathrm{y}_{\mathrm{i}}\right)\right]^{\alpha}\right]\right\}$

$-\sum_{\eta_{i}=0} \frac{\ln \left\{1-\exp \left[-\left[\ln \left(\mathrm{y}_{\mathrm{i}}\right)\right]^{\alpha}\right]\right\}\left\{1-\exp \left[-\left[\ln \left(\mathrm{y}_{\mathrm{i}}\right)\right]^{\alpha}\right]\right\}^{\beta}}{1-\left\{1-\exp \left[-\left[\ln \left(\mathrm{y}_{\mathrm{i}}\right)\right]^{\alpha}\right]\right\}^{\beta}}$

in which $B_{\odot}(y)$ is as defined in (35).

These likelihood equations may not always provide a unique solution and in such cases the maximum of the likelihood function is obtained in the border of the domain of the parameters. Hence, we have obtained the second order partial derivatives of the log-likelihood function of the GLWD and by using R software it has been verified that the values of the second order partial derivatives are negative for the estimated parametric values for both the distributions.

\section{APPLICATIONS}

To illustrate the utility of the $\operatorname{GLWD}(\alpha, \beta)$ as a survival model, we make use of the following three data sets of which the first and second are complete data sets while the third one is a censored data set. All these three data sets arise from biomedical fields.

Data Set 1: Data on remission times for a group of leukemia patients given the drug 6-MP from [16]. 6, 13 ,
$16, \quad 22$
23

Data Set 2: The data on survival of 40 patients suffering from Leukaemia, from the Ministry of Health Hospitals in Saudi Arabia taken from [17].
$15,181,255,418,441,461,516,739,743,789,807$ $865,924,983,1024,1062,1063,1165,1191,1222$, $1222,1251,1277,1290,1357,1369,1408,1455,1478$, $1549,1578,1578,1599,1603,1605,1696,1735,1799$, $1815,1852$.

Data Set 3: Censored data discussed in [18] and given in [15]. The data consist of death times (in weeks) of patients with cancer of tongue with aneuploid DNA profile. The observations are

$1,3,3,4,10,13,13,16,16,24,26,27,28,30,30,32$, $41,51,61 *, 65,67,70,72,73,74 *, 77,79 *, 80 *, 81 *$, $87 *, 87 *, 88 *, 89 *, 91,93,93 *, 96,97 *, 100,101 *$, $104,104 *, 108 *, 109 *, 120 *, 131 *, 150 *, 157,167$, $231 *, 240 *$, and $400 *$, where asterisks denote censored observations.

The maximum likelihood estimates of the parameters of the $\operatorname{GLWD}(\alpha, \beta)$ along with the corresponding values of the standard errors and $P$-values are computed for the three data sets using the $R$ software. The estimated values of the parameters of the $\operatorname{GLWD}(\alpha, \beta)$ along with the values of the standard errors, calculated values of the statistics, and corresponding $\mathrm{P}$-values are presented in Tables 1, $\mathbf{2}$, and 3 respectively.

The variance-covariance matrix of the estimators of the parameters of the $\operatorname{GLWD}(\alpha, \beta)$ corresponding to Data Sets 1, 2, and 3 are respectively

$\Sigma_{(1)}=\left[\begin{array}{cc}106.9564 & 0.9441 \\ 0.9441 & 0.0243\end{array}\right]$,
$\Sigma_{(2)}=\left[\begin{array}{cc}0.0245 & 0.9592 \\ 0.9592 & 107.7790\end{array}\right]$

and

$\Sigma_{(3)}=\left[\begin{array}{ll}0.0029 & 0.0883 \\ 0.0883 & 5.1511\end{array}\right]$.

The performances of the $\operatorname{GLWD}(\alpha, \beta)$ as a survival model is compared with that of some of its related models like the LWD, LIWD, IWD, and the WD by using certain information criteria like the Akaike information criteria (AIC)', 'the Bayesian information criteria (BIC)',

Table 1: Fitted Values of the GLWD Corresponding to Data Set 1

\begin{tabular}{|c|c|c|c|c|}
\hline Parameter & Estimate & Std Error & Calculated Value & P-value \\
\hline \hline$\alpha$ & 1.4717 & 0.1561 & 934283 & $<2.2 e-16$ \\
\hline$\beta$ & 28.6396 & 10.3420 & 2.7693 & 0.0056 \\
\hline
\end{tabular}

Table 2: Fitted Values of the GLWD Corresponding to Data Set 2

\begin{tabular}{|c|c|c|c|}
\hline Parameter & Estimate & Std Error & Calculated Value \\
\hline \hline$\alpha$ & 1.0690 & 0.0122 & 87.25 \\
\hline$\beta$ & 1659.0 & 4.1950 & $395.50<-2.25$ \\
\hline
\end{tabular}


Table 3: Fitted Values of the GLWD Corresponding to Data Set 3

\begin{tabular}{|c|c|c|c|c|}
\hline Parameter & Estimate & Std Error & Calculated Value & P-value \\
\hline \hline$\alpha$ & 0.66283 & 0.05439 & 12.1847 & $<2.2 e-16$ \\
\hline$\beta$ & 12.0451 & 2.2696 & 5.3071 & $1.1 e-07$ \\
\hline
\end{tabular}

'the corrected Akaike information criteria (AICc)' and 'the consistent Akaike information criteria (CAIC)'. The numerical results obtained are summarised in Tables 4 , 5 and 6 . Moreover, to test the significance of the parameter $\beta$, we have carried out the generalized likelihood ratio test (GLRT) procedure for testing the hypothesis $H_{0}$ : $\beta=1$ against the alternative $H_{1}: \beta \neq 1$ using the three data sets. The results of the test procedure are provided in Table 7.

From Tables 4, 5, and 6, it can be observed that the $\operatorname{GLWD}(\alpha, \beta)$ gives a relatively better fit to both complete and censored data sets as compared to the other distributions, since the values of AIC, BIC, AICc, and CAIC are minimum. Also, from Table 7, it is evident that the parameter $\beta$ is significant for all three data sets.

\section{CONCLUSION}

Through this paper we have considered a generalization of the log-Weibull distribution studied by [10], using the name the 'generalized log-Weibull distribution (GLWD)'. Some important theoretical properties of the distribution were investigated including expressions for its characteristic function, moments, certain reliability measures as well as the distribution and moments of order statistics. The maximum likelihood estimation of its parameters for complete as well as censored data sets was considered and the utility of the model in survival analysis was illustrated using three real-life data sets. Based on the present study it can be concluded that the proposed model has much more flexibility compared to many existing models and is relatively

Table 4: Fitting Various Distributions to Data Set 1

\begin{tabular}{|c|c|c|c|c|c|c|}
\hline Model & Estimates & Log-Likelihood & AIC & BIC & AICc & CAIC \\
\hline \hline GLWD & $\alpha=1.4717 \beta=28.6396$ & -22.7589 & 49.5178 & 49.1013 & 53.5178 & 51.1013 \\
\hline LIWD & $c=1.4872$ & -32.4513 & 66.9027 & 66.8486 & 67.7027 & 67.8486 \\
\hline IWD & $c=0.5345$ & -33.287 & 68.575 & 68.521 & 69.375 & 69.521 \\
\hline LWD & $c=0.8601$ & -34.9802 & 71.9603 & 71.9062 & 72.7603 & 72.9062 \\
\hline WD & $c=0.3113$ & -35.7846 & 73.5692 & 73.5151 & 74.3692 & 74.5151 \\
\hline
\end{tabular}

Table 5: Fitting Various Distributions to Data Set 2

\begin{tabular}{|c|c|c|c|c|c|c|}
\hline Model & Estimates & Log-Likelihood & AIC & BIC & AlCc & CAIC \\
\hline GLWD & $\begin{array}{l}\alpha=1.0690 \\
\beta=1659.0\end{array}$ & -316.8007 & 637.6014 & 640.9791 & 637.9257 & 642.9791 \\
\hline IWD & $c=0.1961$ & -394.6037 & 791.2074 & 792.8962 & 791.3126 & 793.8962 \\
\hline WD & $c=0.1165$ & -407.9905 & 817.9810 & 819.6698 & 818.0862 & 820.6698 \\
\hline LIWD & $c=0.7016$ & -419.8682 & 841.7364 & 843.4252 & 841.8416 & 844.4252 \\
\hline LWD & $c=0.4183$ & -433.1577 & 868.3154 & 870.0042 & 868.4206 & 871.0042 \\
\hline
\end{tabular}


Table 6: Fitting Various Distributions to Data Set 3

\begin{tabular}{|c|c|c|c|c|c|c|}
\hline Model & Estimates & Log-Likelihood & AIC & BIC & $\mathrm{AICc}$ & CAIC \\
\hline GLWD & $\begin{array}{c}\alpha=0.6628 \\
\beta=12.0451\end{array}$ & -192.0819 & 388.163 & 392.066 & 388.408 & 394.066 \\
\hline IWD & $c=0.1836$ & -230.2072 & 462.4144 & 464.3656 & 462.4944 & 465.3656 \\
\hline LIWD & $c=0.54727$ & -232.6817 & 467.3634 & 469.3146 & 467.4434 & 470.3146 \\
\hline WD & $c=0.1066$ & -262.2964 & 526.5928 & 528.5440 & 526.6728 & 529.5440 \\
\hline LWD & $c=0.3201$ & -264.5926 & 531.1852 & 533.1364 & 531.2652 & 534.1364 \\
\hline
\end{tabular}

Table 7: The Values of Log-Likelihood Functions and P-Values Corresponding to Data Sets for Testing $H_{0}: \beta=1$ against the Alternate Hypothesis $H_{1}: \beta \neq 1$

\begin{tabular}{|c|c|c|c|c|}
\hline & Likelihood value & $\boldsymbol{\Lambda}$ & df & P value \\
\hline \hline Data Set 1 & -34.9802 & 24.4426 & 1 & $<0.00001$ \\
\hline Data Set 2 & -433.1577 & 232.7140 & 1 & $<0.00001$ \\
\hline Data Set 3 & -264.5926 & 145.0214 & 1 & $<0.00001$ \\
\hline
\end{tabular}

more suitable in handling censored and complete survival data sets, especially from bio-medical applications.

\section{ACKNOWLEDGEMENTS}

The authors would like to express their sincere thanks to the Co-Editor in Chief and all the anonymous referees for their valuable comments on an earlier version of the article, which greatly improved the quality and presentation of the manuscript.

\section{APPENDIX A}

\section{Proof of Result 2.2.}

By definition, the characteristic function of the $\operatorname{GLWD}(\alpha, \beta)$ is

$$
\begin{aligned}
& \phi_{Y}(t)= \\
& \alpha \beta \int_{1}^{\infty} e^{i t y} y^{-1}\left\{1-e^{-[\ln (y)]^{\alpha}}\right\}^{\beta-1} e^{-[\ln (y)]^{\alpha}}[\ln (y)]^{(\alpha-1)} d y .
\end{aligned}
$$

By using the substitution $z=[\ln (y)]^{\alpha}$ and hence expanding the exponential term $e^{\left\{i t e^{z^{\alpha^{-1}}}\right\}}$, we obtain

$$
\begin{aligned}
\phi_{Y}(t) & =\beta \sum_{k=0}^{\infty} \frac{(i t)^{k}}{k !} \int_{0}^{\infty} e^{k z^{\alpha^{-1}}}\left\{1-e^{-z}\right\}^{\beta-1} e^{-z} d z \\
& =\beta \sum_{k=0}^{\infty} \frac{(i t)^{k}(k)^{j}}{j ! k !} \int_{0}^{\infty} z^{j \alpha^{-1}}\left\{1-e^{-z}\right\}^{\beta-1} e^{-z} d z .
\end{aligned}
$$

On expanding the term $\left\{1-e^{-z}\right\}^{\beta-1}$ in (38) using (12) and thereby integrating with respect to $z$, we get (14) in the light of (11).

\section{Proof of Result 2.3.}

By definition, the $r^{\text {th }}$ raw moment of the $\operatorname{GLWD}(\alpha, \beta)$ is

$$
\mu_{r}=\alpha \beta \int_{1}^{\infty} y^{r} y^{-1}\left\{1-e^{-[\ln (y)]^{\alpha}}\right\}^{\beta-1} e^{-[\ln (y)]^{\alpha}}[\ln (y)]^{(\alpha-1)} d y
$$

By using the substitution $z=\ln (y)$ in (39) we get

$$
\begin{aligned}
\mu_{r} & =\alpha \beta \int_{0}^{\infty} e^{r(z)} z^{\alpha-1} e^{-(z)^{\alpha}}\left(1-e^{-(z)^{\alpha}}\right)^{\beta-1} d z \\
& =\sum_{k=0}^{\infty} \frac{r^{k}}{k !} \alpha \beta \int_{0}^{\infty} z^{k} z^{\alpha-1} e^{-(z)^{c}}\left(1-e^{-(z)^{\alpha}}\right)^{\beta-1} d z,
\end{aligned}
$$

which reduces to (15) using (12) and the Binomial theorem, in the light of the equation: 3.381(4) of [19].

\section{REFERENCES}

[1] Aryal G, Elbatal I. Kumaraswamy modified inverse Weibull distribution: Theory and application. Applied Mathematics and Information Sciences 2015; 9: 651-660.

[2] deGusmao F, Ortega E, Cordeiro G. The generalized inverse Weibull distribution. Statistical Papers 2011; 52: 591-619. https://doi.org/10.1007/s00362-009-0271-3

[3] Khan MS, King R. Modified inverse Weibull distribution Journal of Statistics Applications and Probability 2012; 1: 115-131. https://doi.org/10.12785/jsap/010204

[4] Kumar CS, Nair SR. On some aspects of a flexible class of additive Weibull distribution. Communications in Statistics-Theory and Methods 2018; 47: 1028-1049. https://doi.org/10.1080/03610926.2017.1316399 
[5] Nassar MM, Eissa FH. On the exponentiated Weibull distribution. Communications in Statistics-Theory and Methods 2003; 32: 1317-1336. https://doi.org/10.1081/STA-120021561

[6] Mudholkar GS, Srivastava DK. Exponentiated Weibull family for analyzing bathtub failure-rate data. IEEE Transactions on Reliability 1993; 42: 299-302. https://doi.org/10.1109/24.229504

[7] Mudholkar GS, Srivastava DK, Freimer M. The exponentiated Weibull family: A reanalysis of the bus-motor-failure data. Technometrics 1995; 37: 436-445. https://doi.org/10.1080/00401706.1995.10484376

[8] Mudholkar GS, Hutson AD. The exponentiated Weibull family: Some properties and a flood data application. Communications in Statistics-Theory and Methods 1996; 25: 3059-3083. https://doi.org/10.1080/03610929608831886

[9] Shittu OI, Adepoju KA. On the exponentiated Weibull distribution for modeling wind speed in south western Nigeria. Journal of Modern Applied Statistical Methods 2014; 13: 28-31.

https://doi.org/10.22237/jmasm/1398918420

[10] Kumar CS, Nair SR. On some properties of the log-Weibull distribution. Journal of Statistical and Mathematical Engineering 2018; 4: 3-10.

[11] Gradshteyn IS, Ryzhik IM. Tables of Integrals, Series and Products. Academic Press, New York 2007.

[12] Rinne H. The Weibull Distribution: A Handbook. CRC Press, Boca Raton 2008. https://doi.org/10.1201/9781420087444
[13] Church JD, Harris B. The estimation of reliability from stress-strength relationships. Technometrics 1970; 12: 49-54.

https://doi.org/10.1080/00401706.1970.10488633

[14] Gupta RD, Kundu D. Exponentiated exponential family: an alternative to Gamma and Weibull distributions. Biometrical Journal 2001; 43: 117-130.

https://doi.org/10.1002/1521-4036(200102)43:1<117::AID-BI MJ117>3.0.CO;2-R

[15] Klein JP, Moeschberger ML. Survival analysis: techniques for censored and truncated data. Springer Science \& Business Media, New York 2006.

[16] Lawless JF. Statistical Models and Methods for Lifetime Data, Second Edition. John Wiley and Sons, New York 2003. https://doi.org/10.1002/9781118033005

[17] Abouammoh A, Abdulghani S, Qamber I. On partial orderings and testing of new better than renewal used classes. Reliability Engineering and System Safety 1994; 43: $37-41$.

https://doi.org/10.1016/0951-8320(94)90094-9

[18] Sickle-Santanello BJ, Farrar WB, Decenzo JF, Keyhani-Rofagha S, Klein J, Pearl D, Laufman H, O'Toole RV. Technical and statistical improvements for flow cytometric DNA analysis of paraffin-embedded tissue. Cytometry: The Journal of the International Society for Analytical Cytology 1988; 9(6): 594-599. https://doi.org/10.1002/cyto.990090613

[19] Prudnikov AP, Brychkov YA, Marichev OI. Integrals and Series (1,2 and 3). Gordon and Breach Science Publishers, Amsterdam 1986.

Received on 05-01-2021

Published on 16-04-2021

https://doi.org/10.6000/1929-6029.2021.10.02

(C) 2021 Kumar and Nair; Licensee Lifescience Global.

This is an open access article licensed under the terms of the Creative Commons Attribution Non-Commercial License (http://creativecommons.org/licenses/by-nc/3.0/) which permits unrestricted, non-commercial use, distribution and reproduction in any medium, provided the work is properly cited. 